\title{
Laboratory studies of the dental properties of soft drinks
}

\author{
BY T. H. GRENBY, A. PHILLIPS, T. DESAI AND M. MISTRY \\ Department of Oral Medicine and Pathology, United Medical and Dental Schools, Guy's Hospital, \\ London SE1 9RT
}

(Received 12 December 1988 - Accepted 23 March 1989)

\begin{abstract}
The composition and dental properties of eight different soft drinks, representing some of the most popular types used in the UK, were examined. Demineralization experiments were conducted on hydroxylapatite, the basic component of dental enamel, determining calcium dissolving by atomic absorption spectroscopy and phosphorus by u.v. visual spectrophotometry. The titratable acid content of the drinks was found to give a better guide than their $\mathrm{pH}$ to their potential dental erosiveness. The sugar content, in their ready-to-drink form, varied from zero in a low-calorie product up to almost $14 \%$ in a blackcurrant drink, but using a technique with a relatively long contact time, and in the absence of intact dental plaque, the demineralizing action on hydroxylapatite of the acids already in the drinks eclipsed the effects of the acid generated by oral micro-organisms from the sugars in the drinks. The pure citrus juices showed potentially the worst dental properties, followed by the orange and blackcurrant concentrates after dilution to their ready-to-drink form, with least demineralization from the carbonated drinks, and a cola drink giving especially low values.
\end{abstract}

Dental caries: Soft drinks: Teeth

A vast amount of laboratory research has been carried out on the effects of carbohydrate foods in relation to dental caries, but very much less has been done on soft drinks which also contain fermentable carbohydrates. Especially in younger age-groups, there has been a shift away from traditional eating habits towards increasing reliance on snack foods, 'fast foods' and convenience foods accompanied by a range of sweetened or naturally sweet soft drinks. Concern has been expressed over a number of features of this kind of intake pattern and its implications for dental health (Grenby, 1987, 1988), but the emphasis has been on the nutritional imbalance of the solid foods, and not on the properties of the soft drinks.

Both the consumption of such drinks and the number of varieties available have increased enormously in the last few years. Expressed in 'ready-to-drink' terms, the consumption of soft drinks in the UK increased almost ninefold between 1939 and 1984, to 5350 million litres/year, with a total value of about $£ 2000$ million (National Association of Soft Drink Manufacturers Ltd, 1985). This did not include pure fruit juices, which add another 360 million litres, so that the average consumption of soft drinks in that year worked out at over 2 litres/head per week (Jeffries, 1985). The values show no sign of a halt to these trends, with a recent upsurge in the sales of low-calorie drinks, and it has been observed that 'there is no doubt that soft drink consumption continues to go up, up, up, regardless of demographic change, economic recession or anything else' (Burt, 1985).

Excessive use of the drinks has been attacked on two main dental grounds: (1) that as almost all of them are fruit-based or carbonated or both, they may be acidic enough to damage (erode) surfaces of the teeth not covered by dental plaque; (2) that those which contain fermentable carbohydrates (i.e. generally speaking, sugars) may serve as a source of substrate diffusing into the dental plaque, from which micro-organisms inhabiting the plaque can generate the acid that brings about the destructive process of dental caries, initially in the sub-surface of the enamel beneath the plaque. The time-scales of the two processes differ, however, with erosion immediately on contact of the drinks with unprotected 
tooth surfaces, and pre-carious changes taking place in the plaque over a period of a few minutes up to possibly $1 \mathrm{~h}$ or more.

Some studies have been carried out in Scandinavia on the dental properties of a selection of fruit drinks and 'sport drinks' available there (Birkhed, 1984; Meurman et al. 1987), but these did not include any of the squashes and low-calorie products that are now so popular in the UK. A research project was therefore set up to evaluate the dental properties of a representative selection of soft drinks on the market in the UK, in a series of standardized laboratory tests in vitro. The drinks may be divided into three main classes: (1) Natural or reconstituted pure fruit juices, generally drunk undiluted, containing natural sugars identical for the most part with those added in the manufacture of the drinks in classes 2 and 3. (2) Squashes, fruit 'drinks' and cordials: concentrates requiring dilution before being drunk. (3) Carbonated drinks containing carbon dioxide under pressure with fruit or other flavours, e.g. cola.

In addition, those in classes 2 and 3 can be sweetened with either sugars or low-calorie substitutes. Representative examples of each type were chosen for these studies, with those that required dilution being diluted $1: 5(\mathrm{v} / \mathrm{v})$ in a standard manner before use.

The tests were of two types: (1) examination of the drinks themselves, measuring their acidity by $\mathrm{pH}$ and titration, and analysing them for their sugars, protein, calcium and phosphorus contents; (2) measuring the attack of the drinks on hydroxylapatite, the mineral matter of the dental enamel, by chemical analysis of the $\mathrm{Ca}$ and $\mathrm{P}$ dissolving from it under the influence of (a) the acid already in the drinks; (b) the additional acid generated over the same period on incubating the drinks in a medium inoculated with a standardized culture of human dental plaque micro-organisms, although not simulating conditions within the plaque in situ.

\section{METHODS}

The eight different drinks were: pure orange juice, pineapple juice, a 'health-drink' lemon juice, an orange drink, a low-sugar orange drink, a blackcurrant cordial, a carbonated cola drink, a low-calorie carbonated lemonade. The 'health-drink' lemon juice, orange drink, low-sugar orange drink and blackcurrant cordial were diluted $1: 5(\mathrm{v} / \mathrm{v})$ before experiments. Technically the orange drink and low-sugar orange drink were 'drinks' (must contain at least $10 \%$ whole orange and at least $225 \mathrm{~g}$ added sugar $/ 1$ ), and not 'squashes', which must contain at least $25 \%$ orange juice and at least $225 \mathrm{~g}$ added sugar $/ 1$.

\section{Examination of the drinks}

Acidity. This was measured by $\mathrm{pH}$ meter and by titration of the total $\mathrm{H}^{+}$present with 0.05 M-sodium hydroxide (phenol phthalein indicator).

Glucose. This was estimated by the glucose oxidase $(E C 1.1 .3 .4)$ absorptiometric technique (Boehringer Mannheim).

Sucrose. This was determined by a modification of the glucose method, hydrolysing the sucrose by an invertase (EC 3.2.1.26) preparation, estimating the glucose released from it, and subtracting any glucose already present in the drinks.

Fructose. Estimation was by the resorcinol-ammonium ferric sulphate method (Kulka, 1956).

Protein. This was measured by the Coomassie Brilliant Blue G-250 dye-binding technique (Bio-Rad).

$\mathrm{Ca}$. Determination was by atomic absorption spectroscopy, suppressing interference by the addition of lanthanum chloride.

$P$. Determination was by the molybdate absorptiometric method (Allen, 1940).

\section{Studies of the demineralization of hydroxylapatite}

Action of the drinks at timed intervals. Samples $(10.00 \mathrm{ml})$ of the drinks, after dilution as 


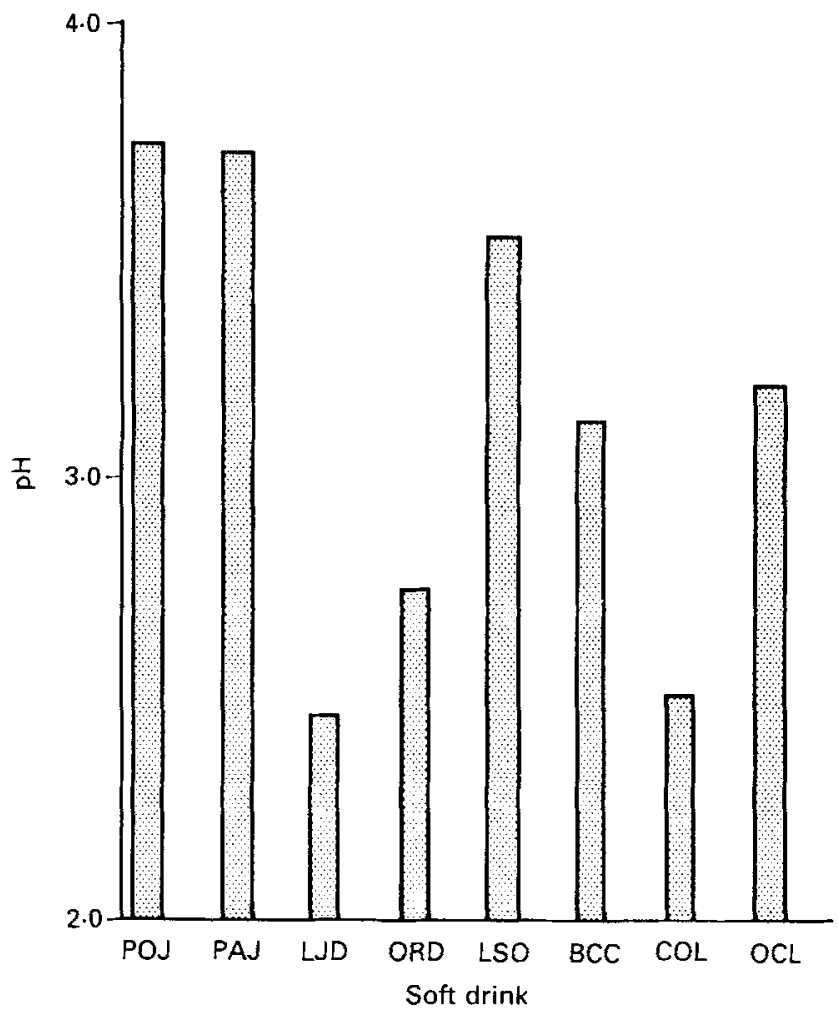

Fig. 1. $\mathrm{pH}$ values of eight soft drinks (in ready-to-drink form). POJ pure orange juice; PAJ, pineapple juice; LJD, 'health drink' lemon juice; ORD, orange drink; LSO, low-sugar orange drink; BCC, blackcurrant cordial; COL, carbonated cola drink; OCL, low-calorie carbonated lemonade.

stated previously if specified, were shaken with $0.010 \mathrm{~g}$ portions of pulverized hydroxylapatite (BDH, Poole, Dorset) at $37^{\circ}$, and portions were withdrawn for the determination of $\mathrm{Ca}$ and $\mathrm{P}$ at the start and after 2, 4, 6 and $24 \mathrm{~h}$.

Experiments with and without oral micro-organisms. Samples $(5.00 \mathrm{ml})$ of the drinks, again diluted as specified, were incubated at $37^{\circ}$ with $0.010 \mathrm{~g}$ hydroxylapatite and $5.00 \mathrm{ml}$ sterile $1 \%$ peptone-P liquid microbiological growth medium (zero carbohydrate, low $\mathbf{P}$ ) with and without the addition of $0.2 \mathrm{ml}$ of a standardized human dental plaque suspension. $\mathrm{Ca}$ and $\mathrm{P}$ analyses were carried out after $24 \mathrm{~h}$.

The sample of dental plaque was collected from a panel of volunteers by working the bristles of sterilized single-tufted brushes into the interstitial spaces between the molar and pre-molar teeth for $15 \mathrm{~s}$, transferring the adherent material to $5.00 \mathrm{ml}$ sterile liquid medium and homogenizing to form a suspension.

All experiments and determinations were replicated, and the results were examined statistically by analysis of variance (ANOVA) where appropriate.

\section{RESULTS}

\section{Examination of the drinks}

Acidity. Results are shown in Figs. 1 and 2. Fig. 1 gives the $\mathrm{pH}$ values. They were all within the range of 2.5 to 3.8 . The two drinks with the highest $\mathrm{pH}$ values were the pure orange and pineapple juices, and the two most acidic were the lemon juice and cola drinks. 


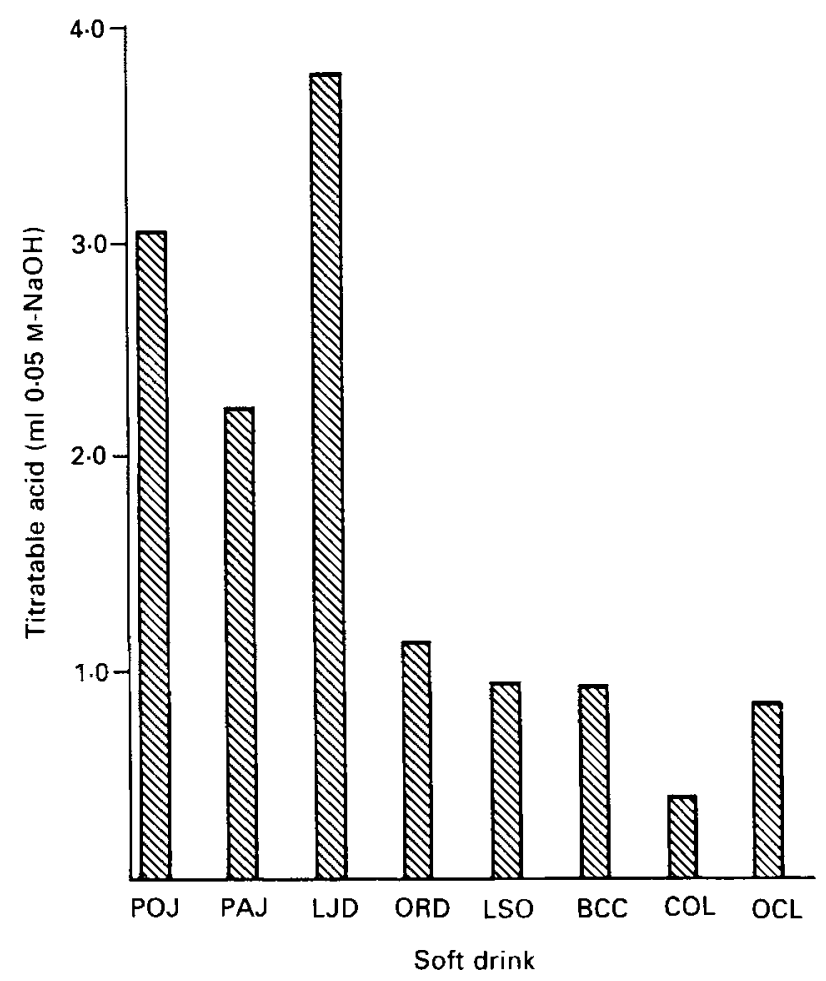

Fig. 2. Total amount of acid present in the eight soft drinks (in ready-to-drink form), estimated by titration with 0.05 M-sodium hydroxide. POJ, pure orange juice; PAJ, pineapple juice; LJD, 'health drink' lemon juice; ORD, orange drink; LSO, low-sugar orange drink; BCC, blackcurrant cordial; COL, carbonated cola drink; OCL, lowcalorie carbonated lemonade.

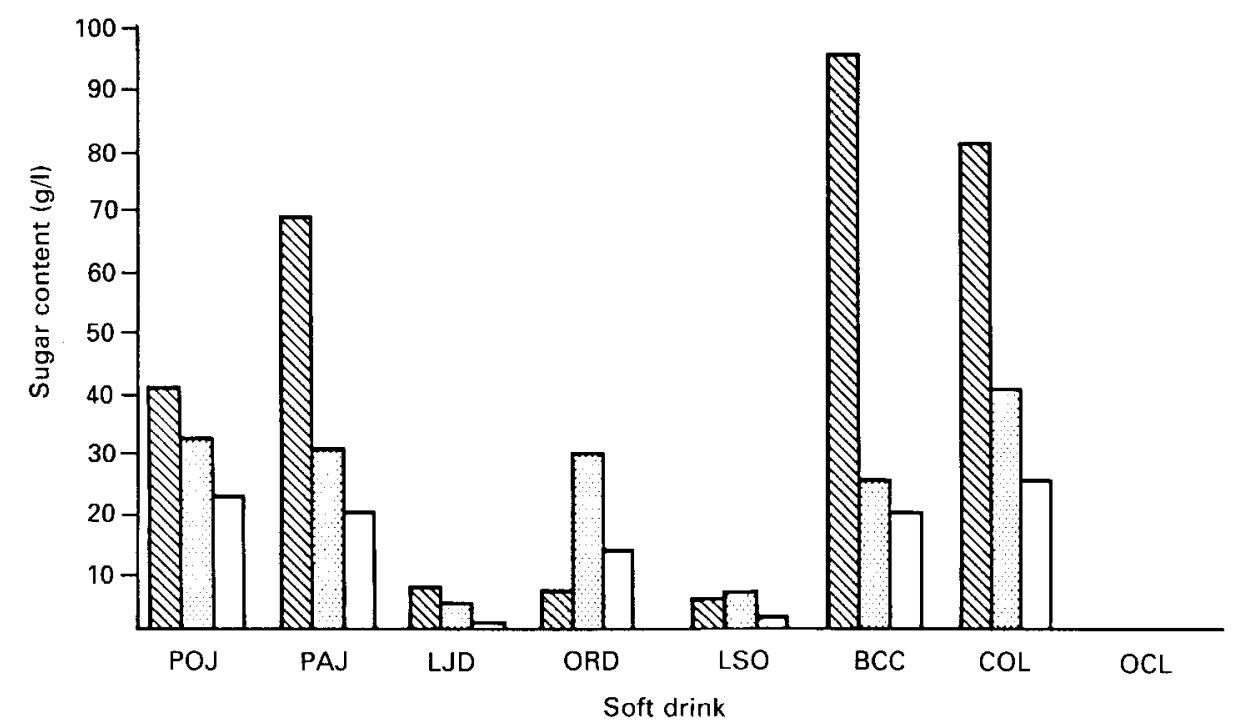

Fig. 3. Sucrose (国), glucose (圈) and fructose ( $\square$ ) contents of eight soft drinks. POJ, pure orange juice; PAJ, pineapple juice; LJD, 'health drink' lemon juice; ORD, orange drink; LSO, low-sugar orange drink; BCC, blackcurrant cordial; COL, carbonated cola drink; OCL, low-calorie carbonated lemonade. 
$\mathrm{Ca}$

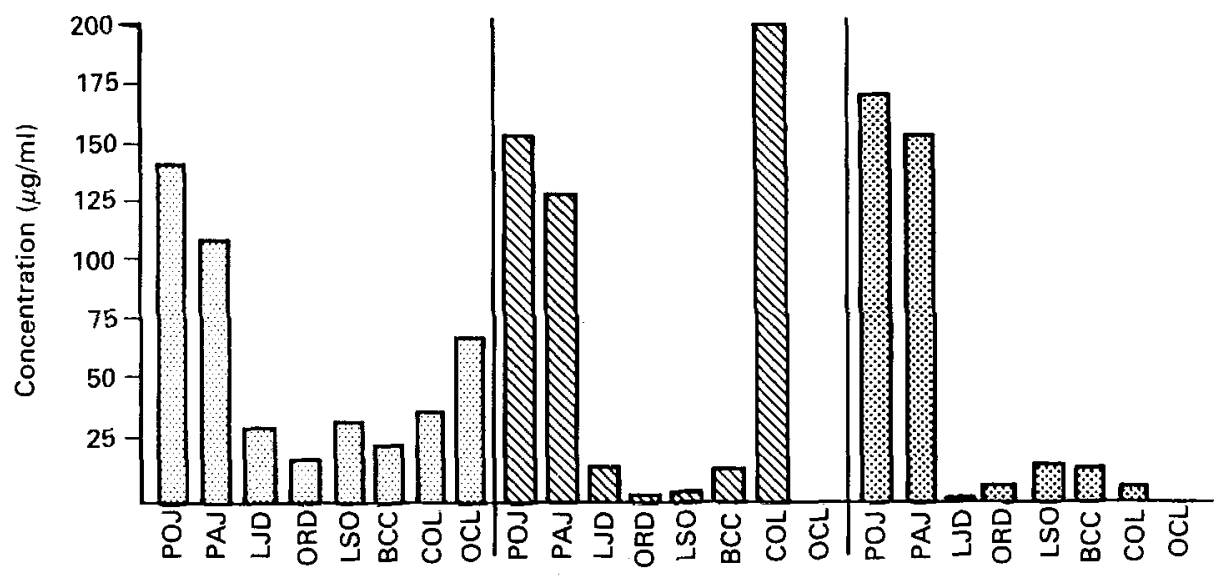

Fig. 4. Calcium, phosphorus and protein contents of eight soft drinks. POJ, pure orange juice; PAJ, pineapple juice; LJD, 'health drink' lemon juice; ORD, orange drink; LSO, low-sugar orange drink; BCC, blackcurrant cordial; COL, carbonated cola drink; OCL, low-calorie carbonated lemonade.

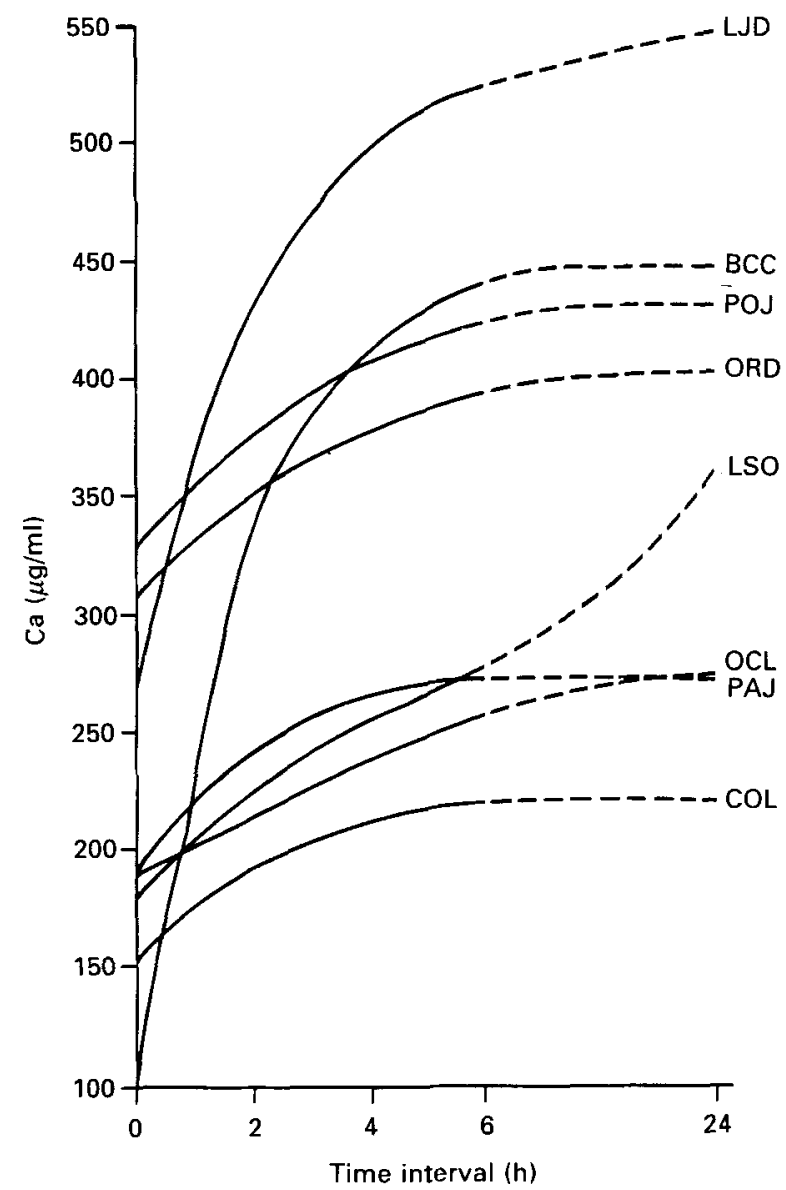

Fig. 5. Calcium dissolving from hydroxylapatite in contact with eight soft drinks, measured at timed intervals at $0,2,4,6$ and 24 h. POJ, pure orange juice; PAJ, pineapple juice; LJD, 'health drink' lemon juice; ORD, orange drink; LSO, low-sugar orange drink; BCC, blackcurrant cordial; COL, carbonated cola drink; OCL, low-calorie carbonated lemonade. 


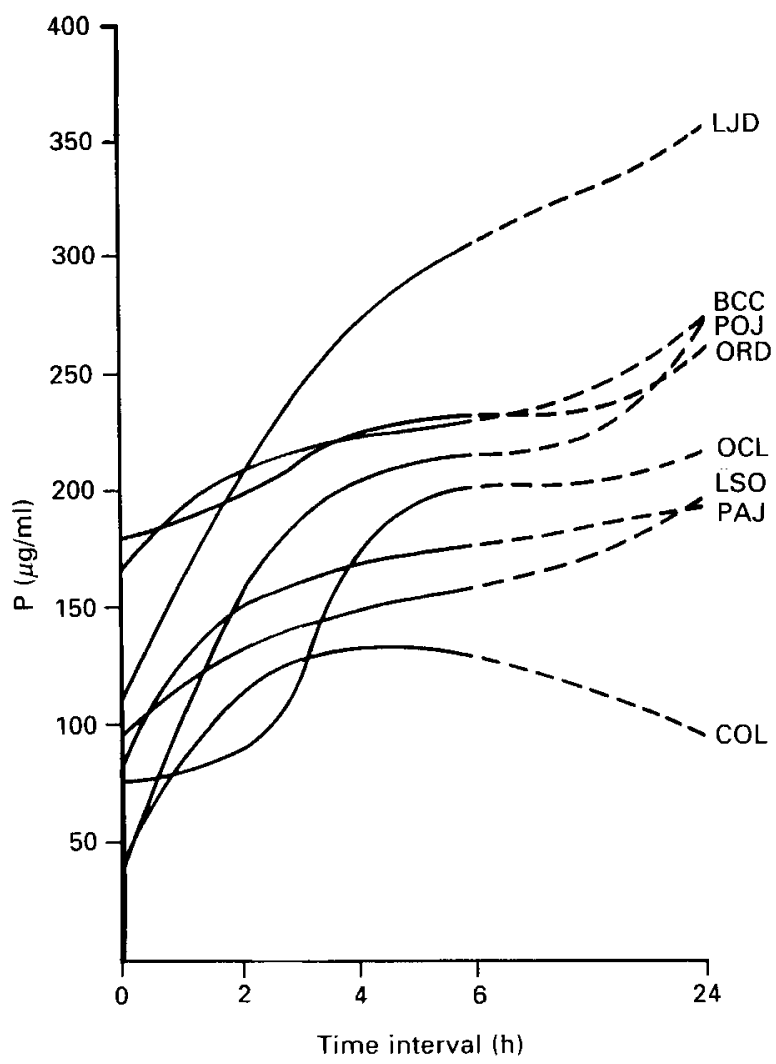

Fig. 6. Phosphorus dissolving from hydroxylapatite in contact with eight soft drinks, measured at timed intervals at $0,2,4,6$ and $24 \mathrm{~h}$. POJ, pure orange juice; PAJ, pineapple juice; LJD, 'health drink' lemon juice; ORD, orange drink ; LSO, low-sugar orange drink ; BCC, blackcurrant cordial; COL, carbonated cola drink; OCL, low-calorie carbonated lemonade.

The total amount of acid present, as measured by titration (Fig. 2), showed much more variation, with a range extending from an equivalent of 0.5 to $3.7 \mathrm{ml} 0.05 \mathrm{M}-\mathrm{NaOH}$. Both the carbonated drinks, the cola and low-calorie lemonade, gave low values. The blackcurrant cordial and both the orange squash-type drinks were also low in total titratable acid, while the three fruit juices had by far the highest values.

Sugars. The concentrations of sucrose, glucose and fructose found in the drinks or given by the manufacturers are shown in Fig. 3. Combining the three to give a total sugar content, the overall concentrations were highest in the blackcurrant cordial, cola and the two pure fruit juices, very low in the lemon juice drink and the low-sugar orange drink, and so low as to be undetectable in the low-calorie lemonade.

The sucrose level was $95 \mathrm{~g} / \mathrm{l}$ in the blackcurrant cordial after dilution to its ready-todrink form. The cola and pure pineapple juice were also relatively high in sucrose.

Glucose and fructose values were generally lower than those for sucrose, and showed less variation, but the lemon juice drink, low-calorie lemonade and the low-sugar orange drink were particularly low in glucose.

$\mathrm{Ca}, \mathrm{P}$ and protein contents. The values are summarized in Fig. 4. All were very low in protein, apart from the two pure fruit juices. These two were also relatively high in both $\mathrm{Ca}$ and $\mathrm{P}$. One noticeable feature was the high level of $\mathbf{P}$ detected in the cola. 


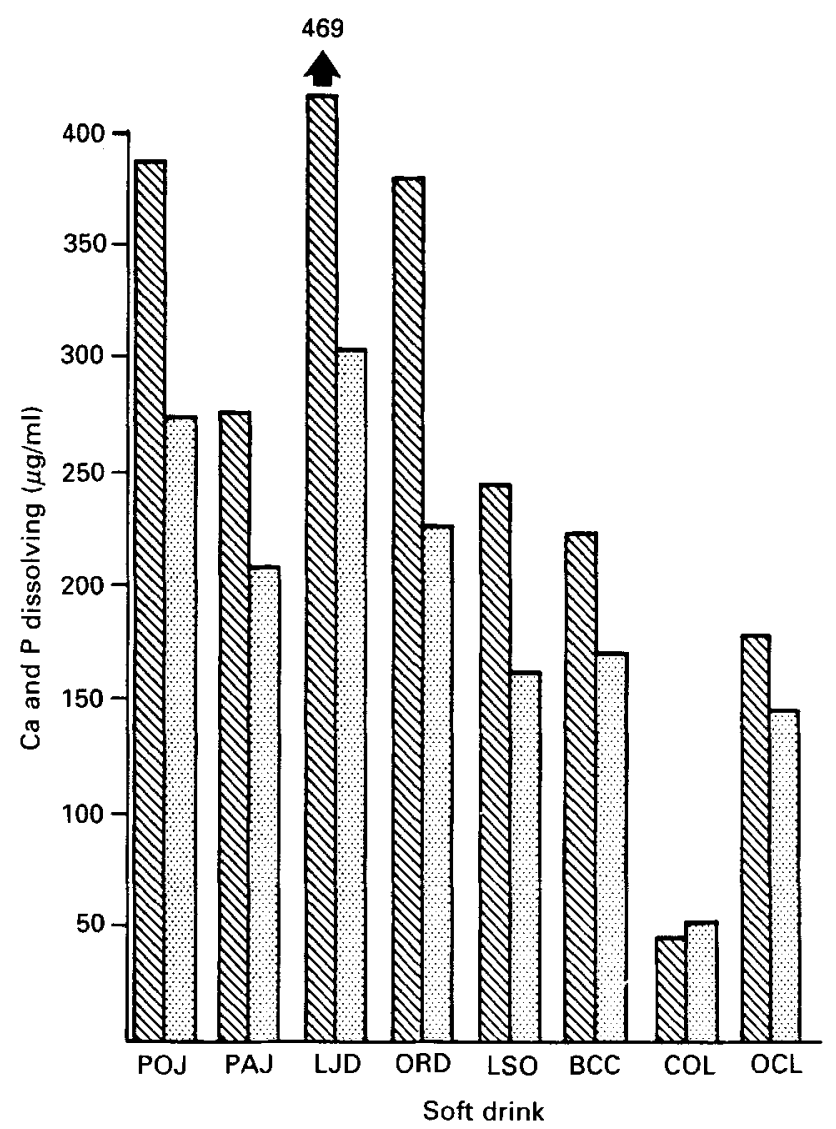

Fig. 7. Demineralization of hydroxylapatite (calcium (国) and phosphorus (图) dissolving) in contact with eight soft drinks after $24 \mathrm{~h}$ at $37^{\circ}$. POJ, pure orange juice; PAJ, pineapple juice; LJD, 'health drink' lemon juice; ORD, orange drink ; LSO, low-sugar orange drink ; BCC, blackcurrant cordial; COL, carbonated cola drink; OCL, lowcalorie carbonated lemonade.

\section{Demineralization of hydroxylapatite}

Analyses at timed intervals. Figs 5 and 6 show trends in the dissolution of $\mathrm{Ca}$ and $\mathrm{P}$ by the drinks over a $24 \mathrm{~h}$ period. Taking the Ca findings (Fig. 5) first, the major changes took place in the first $4-6 \mathrm{~h}$. Least attack on the hydroxylapatite was recorded in the presence of the cola, low-calorie lemonade and pineapple juice. The two pure citrus juices gave high values, with demineralization being especially severe with the lemon juice.

The picture was less clear in the $\mathrm{P}$ analyses (Fig. 6), but the cola again emerged as the least demineralizing, and the lemon juice product as the most demineralizing of all the eight drinks. It can be seen from Figs. 5 and 6 that the initial dissolution rates varied widely, obscuring the differences in $\mathrm{Ca}$ and $\mathrm{P}$ contents between the drinks (Fig. 4).

Demineralization experiments on the effects of the acid in the drinks compared with the acid generated by dental plaque micro-organisms. Results of the incubation of media containing the drinks with hydroxylapatite (no micro-organisms present) are shown in Fig. 7. There was a very wide spread among the different beverages in the amount of demineralization they brought about. The exact values, their standard errors and the levels of significance of the differences between them are given in Table 1. The $\mathrm{Ca}$ and $\mathrm{P}$ findings generally 
Table 1. Levels of statistical significance $\dagger$ of the differences in the demineralization of hydroxylapatite in contact with eight soft drinks for $24 \mathrm{~h}$ at $37^{\circ}$ (four sets of replicates) with no oral micro-organisms present

\begin{tabular}{|c|c|c|c|c|c|c|c|c|}
\hline Soft drink ... & POJ & PAJ & LJD & ORD & LSO & $\mathrm{BCC}$ & $\mathrm{COL}$ & OCL \\
\hline & \multicolumn{8}{|c|}{ Calcium $(\mu \mathrm{g} / \mathrm{ml})$} \\
\hline Mean & 374 & 266 & 471 & 366 & 236 & 216 & 44 & 170 \\
\hline $\mathrm{SE}$ & 14 & 8 & 23 & 9 & 3 & 6 & 2 & 2 \\
\hline POJ $v$ & & $* * *$ & $* * *$ & NS & $* * *$ & $* * *$ & $* * *$ & $* * *$ \\
\hline PAJ $v$. & & & $* * *$ & $* * *$ & NS & *** & **** & $* * *$ \\
\hline LJD $v$. & & & & $* * *$ & $* * *$ & $* * *$ & $* * *$ & $* * *$ \\
\hline ORD $v$. & & & & & $* * *$ & $* * *$ & $* * *$ & $* * *$ \\
\hline LSO $v$ & & & & & & NS & $* * *$ & $* * *$ \\
\hline BCC $v$. & & & & & & & $* * *$ & $* * *$ \\
\hline \multirow[t]{2}{*}{ COL $v$} & & & & & & & & $* * *$ \\
\hline & \multicolumn{8}{|c|}{ Phosphorus $(\mu \mathrm{g} / \mathrm{ml})$} \\
\hline Mean & 267 & 199 & 292 & 218 & 159 & 164 & 51 & 140 \\
\hline & 10 & 4 & 16 & 20 & 8 & 4 & 0 & 0 \\
\hline POJ $v$. & & $* * *$ & NS & $* *$ & $* * *$ & $* * *$ & $* * *$ & $* * *$ \\
\hline PAJ $v$. & & & $* * *$ & NS & $*$ & $* * *$ & $* * *$ & $* * *$ \\
\hline LJD $v$ & & & & $* * *$ & $* * *$ & $* * *$ & $* * *$ & $* * *$ \\
\hline ORD $v$. & & & & & $* * *$ & $* *$ & $* * *$ & $* * *$ \\
\hline LSO $v$ & & & & & & NS & $* * *$ & NS \\
\hline $\mathrm{BCC} v$ & & & & & & & $* * *$ & $* * *$ \\
\hline $\operatorname{COL} v$ & & & & & & & & $* * *$ \\
\hline
\end{tabular}

POJ, pure orange juice; PAJ, pineapple juice; LJD, ' health-drink' lemon juice; ORD, orange drink ; LSO, lowsugar orange drink; BCC, blackcurrant cordial; $\mathrm{COL}$ carbonated cola drink; OCL, low-calorie carbonated lemonade; NS, not significant.

* $P<0.05, * * P<0.01,{ }^{* * *} P<0.001$.

+ By ANOVA.

paralleled each other. It is clear from Fig. 7 that the cola brought about far less demineralization than any of the other drinks. This was followed by the low-calorie lemonade. At the other end of the scale, the two pure citrus juices brought about the greatest demineralization, with the value for $\mathrm{Ca}$ dissolving in the presence of the lemon juice drink being particularly high. As can be seen from Table 1, almost all the differences observed between the drinks were significant or highly significant.

The findings of the experiments in the presence of plaque micro-organisms are shown in Fig. 8, with statistical values in Table 2 . It was first checked by consecutive viable microbial counts that the inoculum grew in the drinks/peptone-P media. Growth was heavy except when the drinks were particularly low in sugars, e.g. the low-calorie lemonade and the lemon juice drink. Microbial multiplication and acid production were highest in the pure orange juice and pineapple juice media. Any small-scale uptake of $\mathrm{Ca}$ and $\mathbf{P}$ by the microorganisms was not measured, but it can be seen from Fig. 8 that the values for $\mathrm{Ca}$ and $\mathrm{P}$ dissolving match those in the absence of micro-organisms (Fig. 7) almost exactly, indicating that under the conditions of these experiments, dissolution of the hydroxylapatite by the acids already in the drinks, rather than by microbially produced acid, is the dominant component in the $\mathrm{Ca}$ and $\mathrm{P}$ values shown in Fig. 8 . 


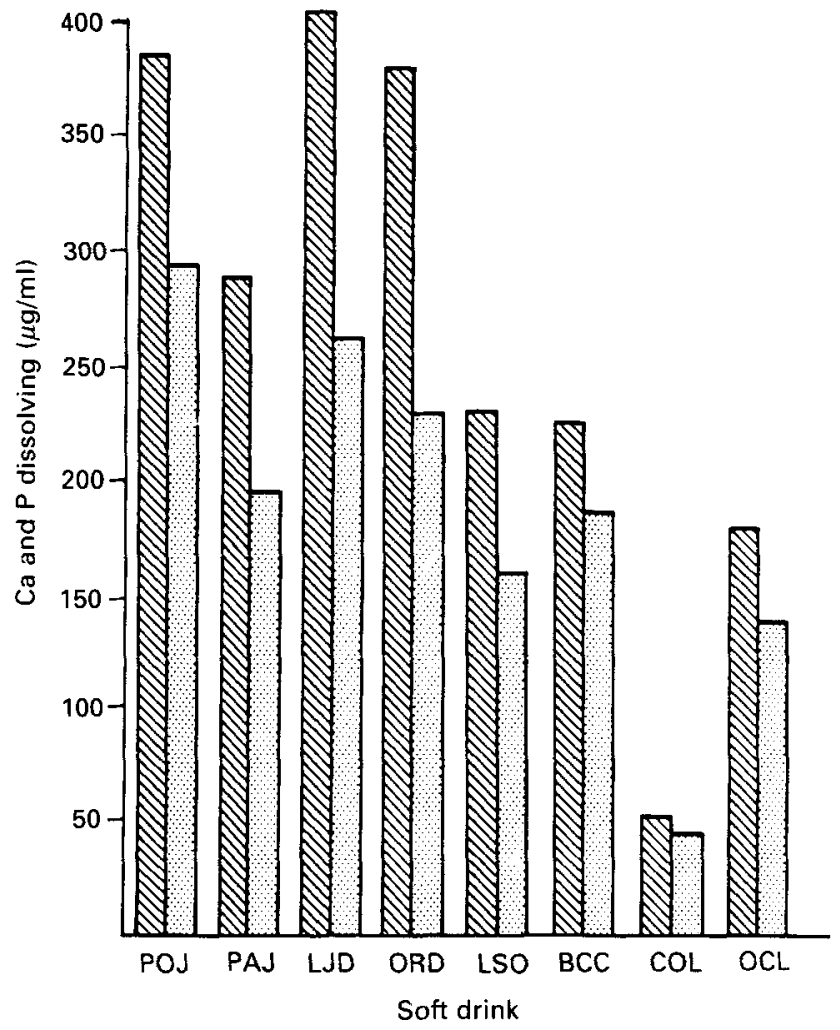

Fig. 8. Demineralization of hydroxylapatite (calcium ( $)$ and phosphorus (图) dissolving) on incubating eight soft drinks with cultures of oral micro-organisms for $24 \mathrm{~h}$ at $37^{\circ}$. POJ, pure orange juice; PAJ, pineapple juice; LJD, 'health drink' lemon juice; ORD, orange drink; LSO, low-sugar orange drink; BCC, blackcurrant cordial; COL, carbonated cola drink; OCL, low-calorie carbonated lemonade.

\section{DISCUSSION}

The main point to emerge from these studies is the wide variation between the drinks in their acidity, sugar content and demineralizing power. In contrast to the conclusions of Birkhed (1984), that commonly used soft drinks all have about the same 'cariogenicity' as far as total sugars, acidity and effect on plaque $\mathrm{pH}$ are concerned, the present findings make it clear that any comments on the collective dental effects of soft drinks must be carefully qualified to distinguish between the different varieties. The eight drinks tested were chosen to represent some of the popular types in use in the UK in 1986, but the market is still expanding, with the appearance of many new products, the dental properties of which have not been evaluated.

One of the two major matters of dental interest is the potential erosiveness of the drinks on dental hard tissues. Erosion is a rapid process that takes place shortly after drinking, so that the dissolution of hydroxylapatite in the earliest part of the time-span shown in Figs. 5 and 6 should have the most relevance to the potential erosiveness of the drinks in vivo. In the past the $\mathrm{pH}$ of the drinks has been taken as the main guide to this, but the results of the present study show that a number of other factors should also be taken into account. pH measurements (Fig. 1) indicated a high $\mathrm{H}^{+}$ion concentration in the lemon juice drink, but a relatively low value for the two other pure fruit juices, orange and pineapple, whereas 
Table 2. Levels of statistical significancet of the differences in the demineralization of hydroxylapatite after incubation at $37^{\circ}$ for $24 \mathrm{~h}$ with the drinks (four sets of replicates) in the presence of oral micro-organisms

\begin{tabular}{|c|c|c|c|c|c|c|c|c|}
\hline Soft drink ... & POJ & PAJ & LJD & ORD & LSO & $\mathrm{BCC}$ & $\mathrm{COL}$ & OCL \\
\hline & \multicolumn{8}{|c|}{ Calcium $(\mu \mathrm{g} / \mathrm{ml})$} \\
\hline Mean & 374 & 277 & 391 & 265 & 224 & 214 & 48 & 172 \\
\hline $\mathrm{SE}$ & 15 & 6 & 19 & 4 & 3 & 5 & 2 & 12 \\
\hline POJ $v$. & & $* * *$ & NS & $* * *$ & $* * *$ & $* * *$ & $* * *$ & *** \\
\hline PAJ $v$. & & & $* * *$ & $* * *$ & $* * *$ & $* * *$ & $* * *$ & $* * *$ \\
\hline LJD $v$ & & & & NS & $* * *$ & $* * *$ & $* * *$ & $* * *$ \\
\hline ORD $v$. & & & & & $* * *$ & $* * *$ & $* * *$ & $* * *$ \\
\hline LSO $v$. & & & & & & NS & $* * *$ & ** \\
\hline $\mathrm{BCC} \nu$. & & & & & & & $* * *$ & $*$ \\
\hline \multirow[t]{2}{*}{$\mathrm{COL} v$} & & & & & & & & $* * *$ \\
\hline & \multicolumn{8}{|c|}{ Phosphorus $(\mu \mathrm{g} / \mathrm{ml})$} \\
\hline Mean & 274 & 186 & 252 & 218 & 150 & 178 & 42 & 133 \\
\hline $\mathrm{SE}$ & 16 & 5 & 0 & 0 & 13 & 12 & 5 & 4 \\
\hline POJ $v$ & & $* * *$ & NS & $* * *$ & $* * *$ & $* * *$ & $* * *$ & $* * *$ \\
\hline PAJ $v$. & & & $* * *$ & $* * *$ & $*$ & NS & $* * *$ & $* * *$ \\
\hline LJD $v$. & & & & $* * *$ & $* * *$ & $* * *$ & $* * *$ & $* * *$ \\
\hline ORD $v$ & & & & & $* * *$ & $* *$ & $* * *$ & $* * *$ \\
\hline LSO $v$. & & & & & & NS & $* * *$ & NS \\
\hline $\mathrm{BCC} v$ & & & & & & & $* * *$ & $* *$ \\
\hline $\operatorname{COL} v$. & & & & & & & & $* * *$ \\
\hline
\end{tabular}

POJ, pure orange juice; PAJ, pineapple juice; LJD, 'health-drink' lemon juice; ORD, orange drink ; LSO, lowsugar orange drink; BCC, blackcurrent cordial; COL, carbonated cola drink; OCL, low-calorie carbonated lemonade; NS, not significant.

* $P<0.05, * * P<0.01, * * * P<0.001$.

$\dagger$ By ANOVA.

the titratable (total ionized + un-ionized) acid emerged as high in all three (Fig. 2). This was reflected in the demineralization values in Fig. 7 and Table 1, where the relatively high erosive potential of all three fruit juices can be seen. Conversely, the cola had one of the lowest $\mathrm{pH}$ values, but contained very little titratable acid and, therefore, brought about far less demineralization of hydroxylapatite than any of the other drinks. The findings are broadly in line with reports of erosion of the dentine by citrus juices, whereas a carbonated cola drink and Ribena (a blackcurrant cordial) produced no effect (Addy et al. 1987).

Taking this a stage further, and summarizing the connection between the acidity and the demineralization findings, the final two graphs, Figs. 9 and 10 , show plots of $\mathrm{pH} v$. demineralization (Fig. 9) and titratable acid v. demineralization (Fig. 10). Fig. 9 suggests that demineralization, as measured by both $\mathrm{Ca}$ and $\mathrm{P}$ dissolving, is at its lowest when the $\mathrm{pH}$ of the drinks is in the region of $3 \cdot 2-3 \cdot 3$, but it rises when the $\mathrm{pH}$ is either above or below this. This may be relevant to the concept put forward by Jackson et al. (1988) and Duke et al. (1988), that drinks formulated with moderate levels of citrate should be potentially less cariogenic than those with no citrate or high levels of citrate.

A simpler relation appears to exist between the titratable acid and $\mathrm{Ca}$ and $\mathbf{P}$ dissolving (Fig. 10), with the demineralization potential of the drinks generally increasing with rises in their total acidity levels. One interesting feature of the plots, however, is that two separate curves can be drawn, the one on the right showing an almost linear rise in $\mathrm{Ca}$ dissolving with titratable acidity in the pure fruit juices, pineapple, orange and lemon, while 


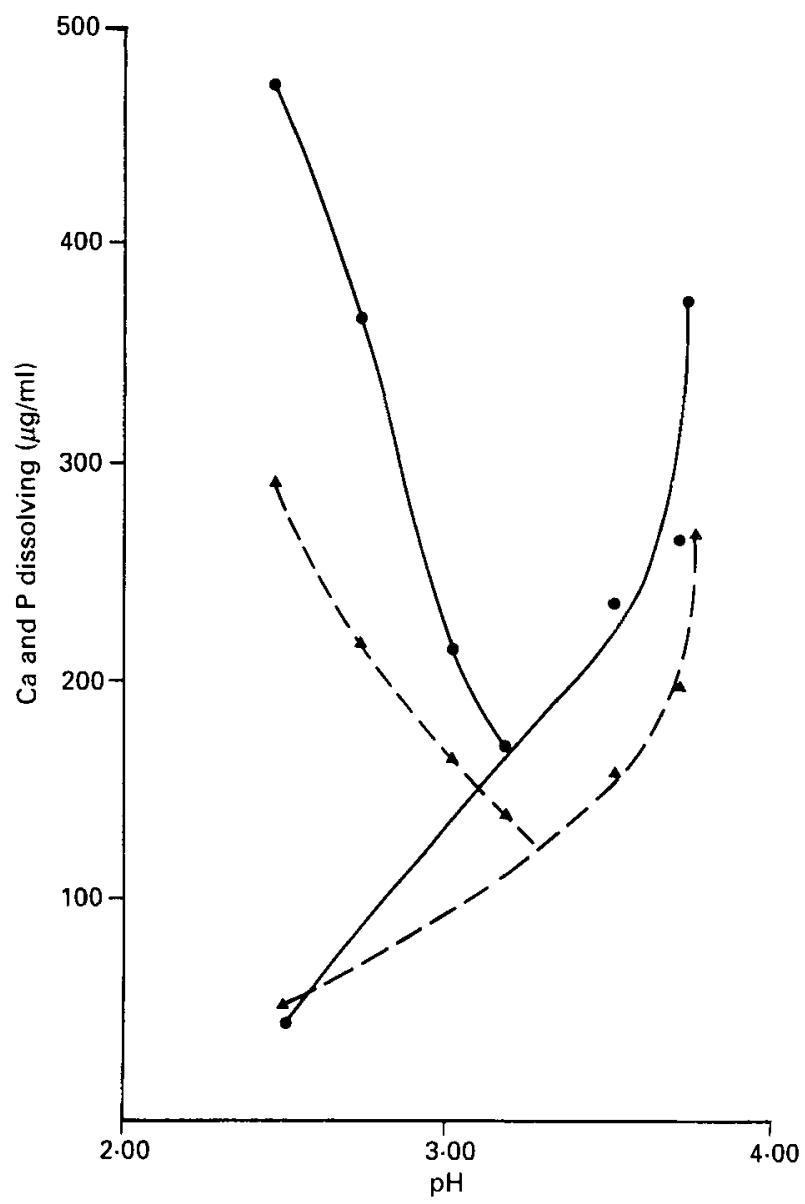

Fig. 9. Plot of the $\mathrm{pH}$ values of eight soft drinks $v$. their demineralizing action on hydroxylapatite (calcium (O) phosphorus (A) dissolving).

the one on the left, for the diluted concentrates and carbonated drinks, shows a different slope, with demineralizing action rising more sharply with increasing titratable acid.

The explanation of these findings is complicated because the drinks are not simple chemical solutions, but contain a variety of components which can influence their properties in different ways. For example, some of the pure fruit juices contained particulate matter which was associated with relatively high $\mathrm{Ca}, \mathrm{P}$ and protein levels (pure orange juice and pineapple juice, Fig. 4). This may assist with a buffering action and possibly tend to maintain a gradual release of acid dissolving the tooth mineral, which could help to explain the differences in the curves between the pure fruit juices and the other drinks in Fig. 10.

Another source of variation in the properties of the drinks is their acid composition. Not only the acidity level (Figs $\mathrm{l}$ and 2), but also the chemical nature and strength $\left(\mathrm{H}^{+}\right.$release) of the acids can vary. The main acid in citrus-fruit drinks is of course citric acid, which has been cited as 'most detrimental' to dental enamel (Meurman et al. 1987), with malic as the main secondary acid. These two are also present in blackcurrant juice, along with ascorbic 


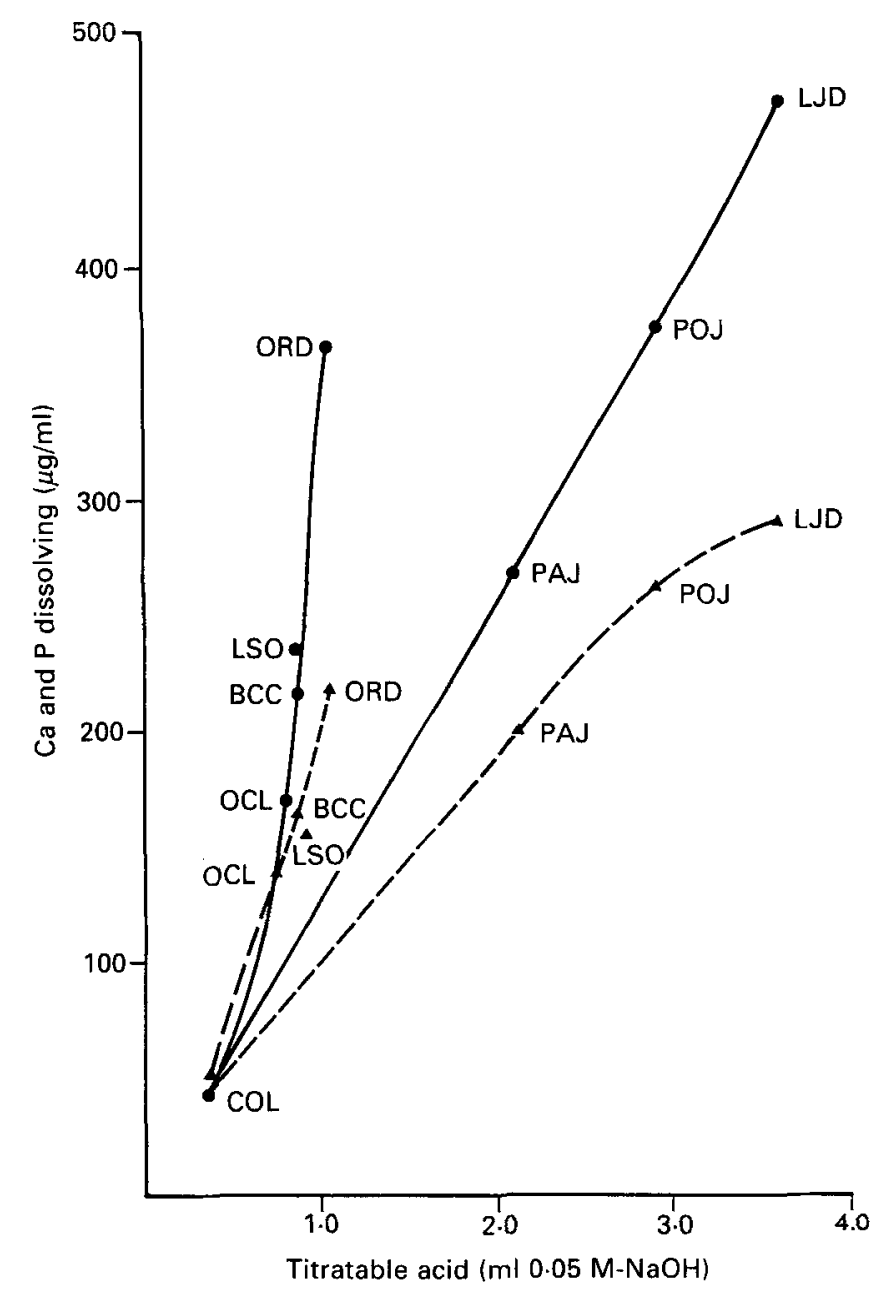

Fig. 10. Plot of titratable acid in the eight soft drinks $v$. their demineralizing action on hydroxylapatite (calcium (O) and phosphorus (A) dissolving). POJ, pure orange juice; PAJ, pineapple juice; LJD, 'health drink' lemon juice; ORD, orange drink; LSO, low-sugar orange drink; BCC, blackcurrant cordial; COL, carbonated cola drink; OCL, low-calorie carbonated lemonade.

acid. In addition, many other acids have been detected in smaller amounts (Shacklady, 1969). Citric, tartaric and fumaric acids have been said to demineralize enamel much more than others, such as ascorbic acid (Kleber et al. 1979). Another factor to be taken into account is the influence of the acids on the oral microflora, as there is some evidence that citric and malic acids at $1 \%$ in sweets can inhibit the activity of oral micro-organisms (Grenby \& Saldanha, 1988). Carbonated drinks, such as the cola and low-calorie lemonade tested in the present work, contain carbon dioxide under pressure, giving a solution of carbonic acid which has $\mathrm{pK}_{\mathrm{a}}$ values at $25^{\circ}$ of 6.37 and $10 \cdot 25$, considerably higher than those of citric acid (3.08, 4.74 and 5.40) and malic acid (3.40 and 5.11), which should therefore exert a greater demineralizing action on hydroxylapatite. The validity of taking the $\mathrm{pK}_{\mathrm{a}}$ of an acid as an indicator of its enamel-dissolving influence has been confirmed by Patel et al. (1987). 
The $\mathrm{Ca}$ and $\mathrm{P}$ contents of the drinks may also help to determine their dental properties. It is said that according to the Law of Mass Action, high concentrations of $\mathrm{Ca}$ and $\mathrm{P}$ in soluble form in fluids (drinks or saliva) bathing the teeth may inhibit the dissolution of dental mineral matter. The importance of this effect is open to question, however: of the eight drinks examined, the cola had the highest $P$ content and was consistently associated with by far the lowest levels of demineralization, while pure orange juice was relatively rich in both $\mathrm{Ca}$ and $\mathrm{P}$, yet showed one of the highest demineralizing activities (see Figs 4-8; Tables 1 and 2). Moreover, values for $\mathrm{Ca}$ and $\mathbf{P}$ in solution in the early stages of the demineralization experiments (Figs 5 and 6) could not have been predicted from the analyses of the drinks (Fig. 4), suggesting a rapid interaction on contact between the drinks and hydroxylapatite. Some evidence for a continued interaction between $\mathrm{Ca}$ in solution and as yet unidentified constituents of the drinks is provided by the $\mathrm{Ca}: \mathrm{P}$ ratios calculated from the values in Figs. 7 and 8, which were generally lower than that of hydroxylapatite.

Turning now from the erosiveness of the drinks to their cariogenic action, this is a cumulative process resulting from the repeated exposure of the dental plaque to sugars taken into the mouth, and their fermentation to acid at localized, susceptible sites on the tooth surface. The information on this that can be derived from the experiments reported here is limited because cariogenic changes taking place in or under the plaque are best observed in vivo with intact plaque and over a much shorter time than that used here. However, one striking observation on incubating the drinks in media containing oral micro-organisms, summarized in Fig. 8, is their similarity to the findings in the absence of any micro-organisms (erosion studies, Fig. 7). This indicates that under the conditions of these experiments the attack on the dental mineral was predominantly by the acids already present in the drinks, rather than by the acids generated in the microbial fermentation of the sugars in the drinks.

This was unexpected in view of the widely differing sugar contents of the drinks (Fig. 3), ranging from none detected at all (low-calorie lemonade) up to almost $14 \%$ (blackcurrant cordial in ready-to-drink form). The drinks that were low in sugars were low-calorie lemonade, low-sugar orange drink, lemon health drink and the orange drink, but there was no evidence from the incubation experiments (Fig. 8) that these had particularly advantageous dental properties. It can be seen that two of the pure fruit juices, orange and pineapple, showed appreciable sucrose, glucose and fructose contents: there is no reason to suppose that because they are perceived as 'natural' products they have any advantage over the 'man-made' drinks in respect of their sugar content. One popular misconception is that fruit juices are high in fructose or 'fruit sugar', and are therefore better for the teeth than other beverages. However, fructose is about as cariogenic as glucose (Grenby, 1983); it was present in the drinks in only low concentrations, and moreover, even those relatively small amounts may have originated from the hydrolysis of sucrose under the prevailing acidic conditions in the drinks.

On occasional exposure, in the comparatively short time the drinks remain in the mouth, their erosive properties are almost certainly of greater dental significance than their cariogenic potential as governed by their sugar content, although of course it must be borne in mind that if they are taken into the mouth frequently, as part of an eating or snacking pattern including many other sugar-containing items, the cumulative long-term effect is likely to be an increased risk of dental caries. Findings from intra-oral $\mathrm{pH}$ telemetry support the view that acidic, sugary beverages may promote both dental caries and erosion if consumed frequently (Imfeld, 1983). Under circumstances of habitual consumption, sugarless or reduced-sugar beverages, such as the low-calorie lemonade and the low-sugar orange drink, would be expected to have a lower cariogenic potential than their sugarcontaining counterparts. 
With the benefit of hindsight, improvements could have been made to the experiments to make them more relevant to intra-oral conditions. In particular, the early stages in the demineralization process shown in Figs. 5 and 6, starting from the initial contact of the drinks with the tooth material, need to be studied in greater detail. Nevertheless consistent and very clear differences between the various kinds of drinks in their potential dental effects were seen, with the citrus juices and drinks, except for the low-sugar orange drink, appearing to pose the greatest threat, and the best results coming from the carbonated drinks, with the cola emerging as theoretically the least damaging of all.

\section{REFERENCES}

Addy, M., Absi, E. G. \& Adams, D. (1987). Dentine hypersensitivity. The effects in vitro of acids and dietary substances on root-planed and burred dentine. Journal of Clinical Periodontology 14, 274-279.

Allen, R. J. L. (1940). The estimation of phosphorus. Biochemical Journal 24, 858-864.

Birkhed, D. (1984). Sugar content, acidity and effect on plaque pH of fruit juices, fruit drinks, carbonated beverages and sport drinks. Caries Research 18, 120-127.

Burt, B. A. (1985). The future of the caries decline. Journal of Public Health Dentistry 45, 261-269.

Duke, S. A., Molyneux, K. \& Jackson, R. J. (1988). The effect of citrate in drinks on plaque pH. British Dental Journal 64, 80-82.

Grenby, T. H. (1983). Nutritive sucrose substitutes and dental health. In Developments in Sweeteners, vol. 2, pp. 51-88 [T. H. Grenby, K. J. Parker and M. G. Lindley, editors]. London: Applied Science.

Grenby, T. H. (1987). Dental and nutritional properties of snack foods and soft drinks. Deutsche Zahnärztliche Zeitschrift 42, S104-S106.

Grenby, T.H. (1988). The nutritive properties and dental decay potential of snack foods. Frontiers of Gastrointestinal Research 14, 71-78.

Grenby, T. H. \& Saldanha, M. G. (1988), Comparison of Lycasin ${ }^{\circledR}$ versus sucrose sweets in demineralisation studies of human enamel and hydroxylapatite. Caries Research 22, 269-275.

Imfeld, T. N. (1983). Identification of Low Caries Risk Dietary Components, pp. 165-174. Basel: Karger.

Jackson, R. J., Duke, S. A., Molyneux, K. \& Poile, S. (1988). Effect of citrate on the potential cariogenicity of drinks. Caries Research 22, 110 Abstr.

Jeffries, D. A. (1985). Drink Market Update No. 1. Leatherhead: Food Research Association.

Kleber, C. J., Putt, M. S. \& Muhler, J. C. (1979). Changes in salivary pH after ingestion of sorbitol tablets containing various food acidulants. Journal of Dental Research 58, $1564-1565$.

Kulka, R. G. (1956). Colorimetric estimation of ketopentoses and ketohexoses. Biochemical Journal 63, 542-548.

Meurman, J. H., Rytomaa, I., Kari, K., Laakso, T. \& Murtomaa, H. (1987). Salivary pH and glucose after consuming various beverages, including sugar-containing drinks. Caries Research 21, 353-359.

National Association of Soft Drink Manufacturers Ltd (1985). Factsheet no. 8. Twickenham, Middx: NASDM Ltd.

Patel, M. V., Fox, J. L. \& Higuchi, W. I. (1987). Effect of acid type on kinetics and mechanism of dental enamet demineralisation. Journal of Dental Research 66, 1425-1430.

Shacklady, J. (1969). Fruit juices and fruit juice beverages. In Food Industries Manual, 20th ed, pp. $257-258$ [A. H. Woollen, editor]. London: Leonard Hill. 